Article

\title{
Composite Properties and Micromechanical Analysis of Highly Ductile Cement Composite Incorporating Limestone Powder
}

\author{
Jung Hwan Hyun ${ }^{1}$, Bang Yeon Lee ${ }^{2}$ (D) and Yun Yong Kim ${ }^{3, *}$ \\ 1 Department of Civil Engineering, Chungnam National University, Daejeon 34134, Korea; \\ mildface@naver.com \\ 2 School of Architecture, Chonnam National University, 77 Yongbong-ro, Buk-gu, Gwangju 61186, Korea; \\ bylee@jnu.ac.kr \\ 3 Department of Civil Engineering, Chungnam National University, Daejeon 34134, Korea \\ * Correspondence: yunkim@cnu.ac.kr; Tel.: +82-42-821-7004
}

Received: 22 November 2017; Accepted: 18 January 2018; Published: 23 January 2018

\begin{abstract}
This paper presents the results of an experimental study on the effect of limestone powder on the compressive strength, tensile behavior, and micromechanical parameters of a highly ductile cement composite incorporating limestone powder. Four mixtures were determined according to the replacement ratio of cement with limestone powder. A series of experiments including compressive strength, uniaxial tension, single fiber pullout, and matrix toughness tests were performed. Test results showed that the strength (compressive, initial cracking, and tensile strength) decreased, and that the tensile strain capacity increased, with an increase of the replacement ratio of cement with limestone powder. Micromechanical tests and analysis supported the uniaxial tension test result.
\end{abstract}

Keywords: composite; ductility; fiber; limestone powder; micromechanical analysis

\section{Introduction}

Since Portland cement was developed in the 1820s, concrete has been used as the main construction material in construction fields due to its excellent economic feasibility, relatively high compressive strength, and durability [1-3]. However, it has inherently low tensile strength (about 10\% of compressive strength), which results in susceptibility to cracking, and shows brittle behavior under tensile load, compared with compressive load.

Recently, there is growing interest in highly ductile cement composites (HDCC) which is a class of cement mortar-based composite reinforced by synthetic fibers of less than $2 \%$ volume. This combination shows high tensile strain capacity, over $3 \%$, which is approximately three hundred times greater than that of normal concrete [4-7]. Unlike quasi-brittle concrete materials, HDCC shows tensile strain hardening under uniaxial tensile load. Such superior tensile behavior compared with normal concrete or fiber-reinforced concrete is achieved by proper selection of materials such as binder, aggregate, and fiber; and optimization of the mixture proportions based on micromechanics and steady-state cracking theory. The micromechanics and steady-state cracking theory are the theoretical backgrounds of the multiple cracking and strain-hardening behaviors of HDCC [8,9]. Based on these theories, it is possible to select materials and determine mixture proportions to achieve a composite with high tensile-strain capacity and controlled crack width.

In most types of HDCC, cement is used as the main binding material. However, a previous report indicated that the cement industry produces approximately $5 \%$ of the total carbon dioxide produced by human [10]. Therefore, many studies are being carried out to reduce the use of cement by 
partially replacing the cement with inorganic binders such as fly ash, blast furnace slag, and limestone powder, which are industrial by-products [11-13]. Limestone powder was assumed to be an inert filler before the 1980s, however, recent studies showed that calcium carboaluminate hydrates precipitate during the hydration of Portland limestone cement. Moreover, there is an interaction between calcium carbonate and tricalcium silicate [14]. Previous literature reported that the fluidity of the concrete was improved and cost efficiency improved by incorporating limestone powder $[15,16]$. The amount of superplasticizer in concrete can be reduced by incorporating limestone powder while maintaining fluidity; although the performance depends on the particle size distribution and particle shape as well as surface characteristics of the limestone powder [17]. Zhou et al. (2010) also reported that the flexural deflection capacity and the tensile strain capacity of engineered cementitious composites (ECC) increased as the limestone powder content increased [18]. Although the feasibility of adapting limestone powder for HDCC has been demonstrated, study of the effects of limestone powder on the tensile behavior of HDCC, in terms of micromechanics, is still limited.

The purposes of this study were to investigate the effects of limestone powder on the composite properties of HDCCs, in which the cement was partially replaced by limestone powder, and to investigate the underlying reasons for differences in the tensile behavior observed in the composites by performing matrix fracture and single fiber pullout tests and micromechanical analysis.

\section{Materials and Methods}

\subsection{Materials and Mixture Proportions}

Polyvinyl-alcohol (PVA) was used as a reinforcing fiber for the HDCCs investigated in this study and the properties of PVA fiber are listed in Table 1. Type I ordinary Portland cement with a density of $3.15 \mathrm{~g} / \mathrm{cm}^{3}$ was used as the main binding material. The limestone powder was used as a replacement for cement. The density and fineness of the limestone powder was $2.83 \mathrm{~g} / \mathrm{cm}^{3}$ and $4521 \mathrm{~cm}^{2} / \mathrm{g}$, respectively. Silica sand with a density of $2.65 \mathrm{~g} / \mathrm{cm}^{3}$ and an average size of $100 \mu \mathrm{m}$ was used as fine aggregate. Coarse aggregate was excluded to improve the tensile behavior because it increases the fracture toughness of the matrix. Superplasticizer (SP), viscosity modifying agent (VMA), and deformer blended with hydrocarbons and polyglycols were added as admixture to improve the dispersion of the PVA fiber within the mixtures.

The mix proportions of the HDCCs investigated in this study are listed in Table 2. The HDCC0 mixture was the control mixture and did not contain limestone powder. HDCC15, HDCC30 and HDCC45 were designed to investigate the effect of replacement of cement with various amounts of limestone powder, on the composite properties and micromechanical properties of the HDCC.

Table 1. Properties of polyvinyl-alcohol (PVA) fiber.

\begin{tabular}{ccccccc}
\hline Fiber & $\begin{array}{c}\text { Density } \\
\left(\mathrm{g} / \mathbf{m m}^{\mathbf{3}}\right)\end{array}$ & $\begin{array}{c}\text { Length } \\
(\mathbf{m m})\end{array}$ & $\begin{array}{c}\text { Diameter } \\
(\mu \mathrm{m})\end{array}$ & $\begin{array}{c}\text { Tensile } \\
\text { Strength }(\mathbf{M P a})\end{array}$ & $\begin{array}{c}\text { Young's } \\
\text { Modulus (GPa) }\end{array}$ & $\begin{array}{c}\text { Elongation } \\
(\mathbf{\%})\end{array}$ \\
\hline PVA & 1.30 & 12 & 40 & 1560 & 41 & 6.5 \\
\hline
\end{tabular}

Table 2. Mix proportion of highly ductile cement composites (HDCCs) (proportion by weight of cement and limestone powder).

\begin{tabular}{ccccccccc}
\hline \multirow{2}{*}{ Mix } & \multirow{2}{*}{ Water } & Cement & \multirow{2}{*}{$\begin{array}{c}\text { Limestone } \\
\text { Powder }\end{array}$} & Sand & \multicolumn{3}{c}{ Admixtures } & \multirow{2}{*}{$\begin{array}{c}\text { PVA Fiber } \\
\text { (by vol.) }\end{array}$} \\
\hline HDCC0 & 0.45 & 1 & & & SP & VMA & Deformer & \\
HDCC15 & 0.45 & 0.85 & 0.15 & 0.80 & 0.0031 & 0.0020 & 0.0020 & 2 \\
HDCC30 & 0.45 & 0.70 & 0.30 & 0.80 & 0.0026 & 0.0026 & 0.0020 & 2 \\
HDCC45 & 0.45 & 0.55 & 0.45 & 0.80 & 0.0025 & 0.0030 & 0.0020 & 2 \\
\hline
\end{tabular}

Note: Mass ratios of cement and limestone powder except fiber. 


\subsection{Specimen Preparation}

To evaluate the compressive strength and uniaxial tensile behavior of HDCCs, nine cylindrical specimens for each mixture with a diameter of $100 \mathrm{~mm}$ and a height of $200 \mathrm{~mm}$, and three dog-bone shaped specimens (Figure 1a) made in accordance with the recommendations of the Japan Society of Civil Engineers [19] were cast, and all the specimens were covered with plastic sheeting to prevent evaporation of water. All specimens were demolded at the age of three days, and cured in water at a temperature of $23{ }^{\circ} \mathrm{C} \pm 3{ }^{\circ} \mathrm{C}$ until being tested. Figure $1 \mathrm{~b}$ shows the dimensions of the specimen used for the single-fiber pullout test, in which a single PVA fiber was embedded in the matrix. The embedded fiber length was $1 \mathrm{~mm}$. Five specimens for each mixture were prepared in a small acrylic mold. These specimens were demolded at the age of three days, and cured in water at a temperature of $23^{\circ} \mathrm{C} \pm 3{ }^{\circ} \mathrm{C}$ until tested. Figure 1c shows the dimensions of the specimen used for the matrix fracture toughness test (based on the wedge-splitting method) [5]. Three specimens were prepared for each mixture.

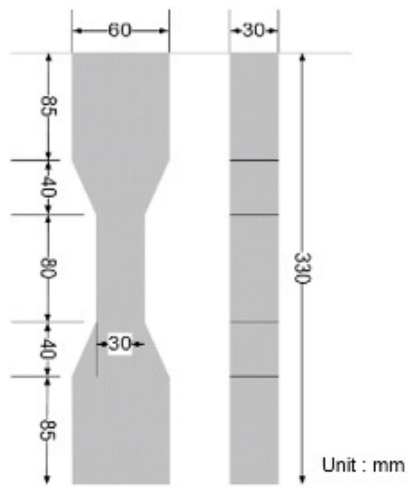

(a)

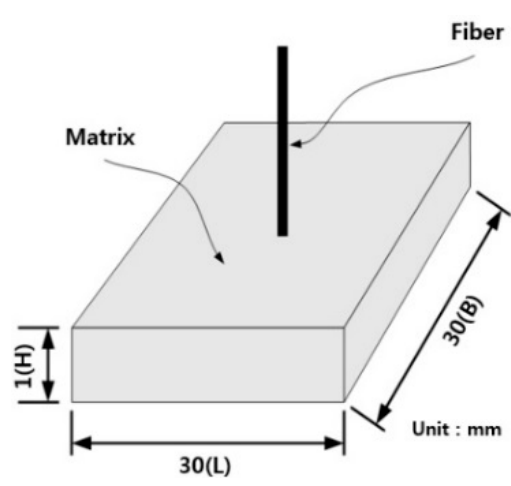

(b)

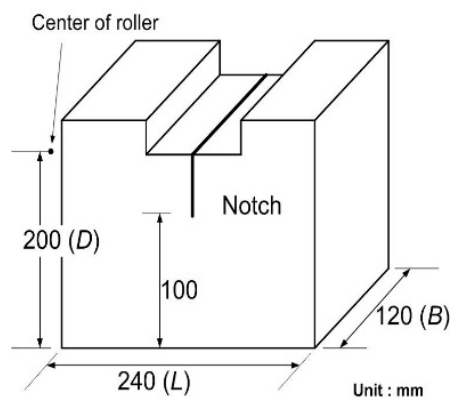

(c)

Figure 1. Specimen for (a) uniaxial tension test; (b) single fiber pullout test; and (c) matrix fracture test.

\subsection{Compressive Strength and Uniaxial Tension Tests}

The compressive strength of the HDCCs was measured using a universal testing machine in accordance with ASTM C39 [20]. Samples were tested at ages of 7, 14, and 28 days. Figure 2a shows the uniaxial tension test setup. Tensile load was applied to the specimen using a universal testing machine with $250 \mathrm{kN}$ capacity at 28 days. The specimens were loaded with a constant cross head speed $(0.1 \mathrm{~mm} / \mathrm{min})$, and the loading force and elongation were measured to calculate the stress and strain of specimen. Two linear variable differential transducers with a gage length of $80 \mathrm{~mm}$ were attached to both sides of the specimen to measure the elongation.

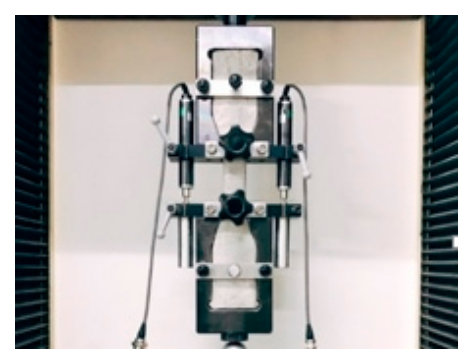

(a)

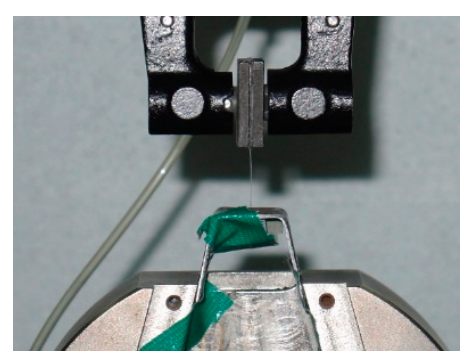

(b)

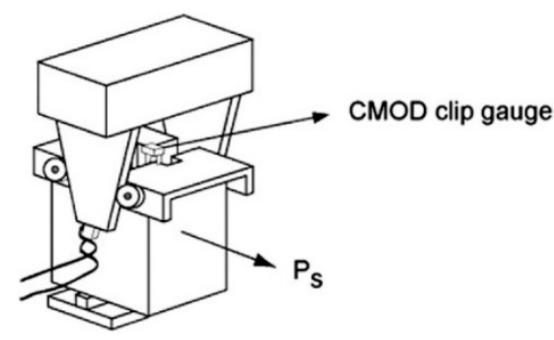

(c)

Figure 2. Experimental setup for (a) uniaxial tension test; (b) single fiber pullout test; and (c) matrix fracture test. 


\subsection{Fiber Pullout Test and Matrix Fracture Test}

A single fiber pullout test was employed to measure the properties of the interface between the fiber and the matrix [21]. Figure $2 b$ illustrates the experimental setup. Protruding PVA fiber was wrapped with an acrylic film and fixed to the grip attached to the load cell of the test equipment. The test was carried out under displacement control at the speed of $0.2 \mathrm{~mm} / \mathrm{min}$. Figure 2c shows the test setup for the matrix fracture toughness test [22]. A clip gauge for measuring the crack-mouth-opening displacement (CMOD) was installed and the CMOD was measured according to an increase in the load using the displacement control method $(0.001 \mathrm{~mm} / \mathrm{s})$ to calculate the fracture toughness $\left(K_{m}\right)$ using Equation (1).

$$
\begin{gathered}
K_{m}=\frac{P_{c}}{b \sqrt{d}} F(\alpha), \\
F(\alpha)=29.6 \alpha^{0.5}-185.5 \alpha^{1.5}+665.7 \alpha^{2.5}-1017.0 \alpha^{3.5}+638.9 \alpha^{4.5},
\end{gathered}
$$

where, $P_{c}$ is the critical (peak) load, $b$ is the thickness of a specimen, $d$ is the length from bottom face of a specimen to roller axis, $\alpha$ is $a / d$, and $a$ is the crack length.

\section{Results and Discussion}

\subsection{Compressive Strength and Uniaxial Tensile Behavior}

Figure 3 shows the compressive strength of each mixture. As shown in Figure 3, all mixtures showed compressive strength over $30 \mathrm{MPa}$ (a compressive strength level widely used for structural concrete) at an age of 28 days. The HDCC 0 specimen showed the highest compressive strength (48.8 MPa on average at 28 days). The compressive strength decreased sequentially as the amount of cement replaced with limestone powder increased. This may be attributed to the low hydration rate of limestone powder. As expected, the compressive strength of all specimens increased with age.

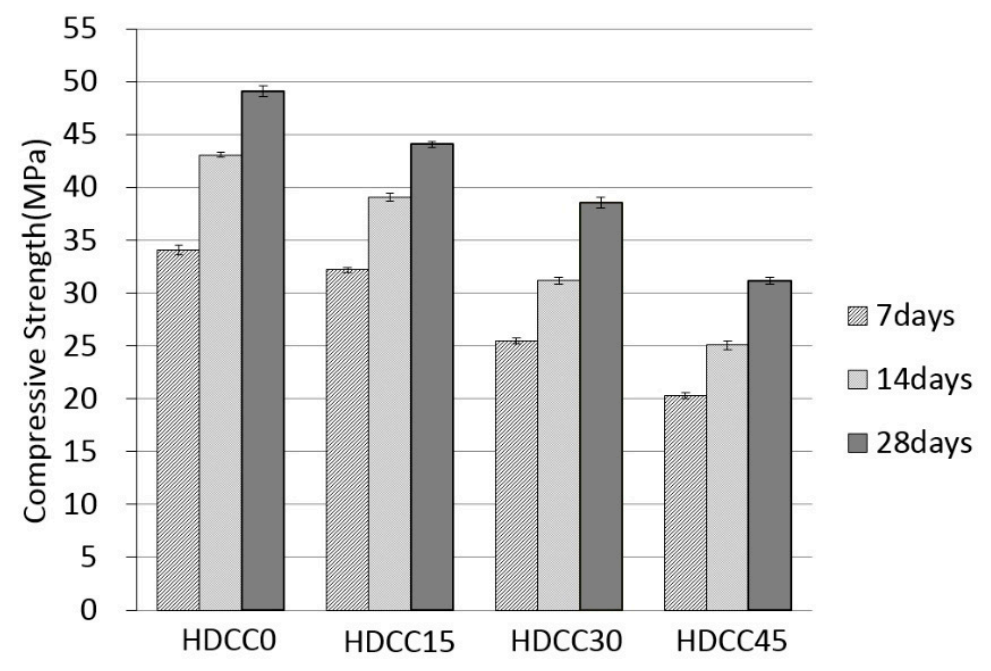

Figure 3. Compressive strength of highly ductile cement composites (HDCCs).

Figure 4 shows the tensile stress-strain curves of each HDCC mixture. All mixtures showed apparently pseudo strain-hardening behavior under uniaxial tensile load. As shown in Figure 4, stress drop can be observed when cracks occurred, which means that all specimens had multiple micro-cracks.

The initial cracking strength, tensile strength, and tensile strain capacity of each mixture are listed in Table 3. The tensile strength and tensile strain capacity were defined as the maximum tensile stress and the tensile strain corresponding to the tensile strength, respectively. Similar to compressive strength test results, the initial cracking strength decreased as the replacement ratio of limestone powder increased. This is attributable to the fact that the cracking strength depends on the matrix 
properties (i.e., the strength of matrix and flaw size in the matrix) [23]. Although the initial cracking strength depends on the replacement ratio of cement with limestone powder, all mixtures showed similar ratios of initial cracking strength to compressive strength. The ratios of initial cracking strength to compressive strength of each mixture HDCC0, HDCC15, HDCC 30, and HDCC45, were $8.2 \%, 8.3 \%$, $8.3 \%$ and $8.3 \%$, respectively, which are similar to that of normal concrete.

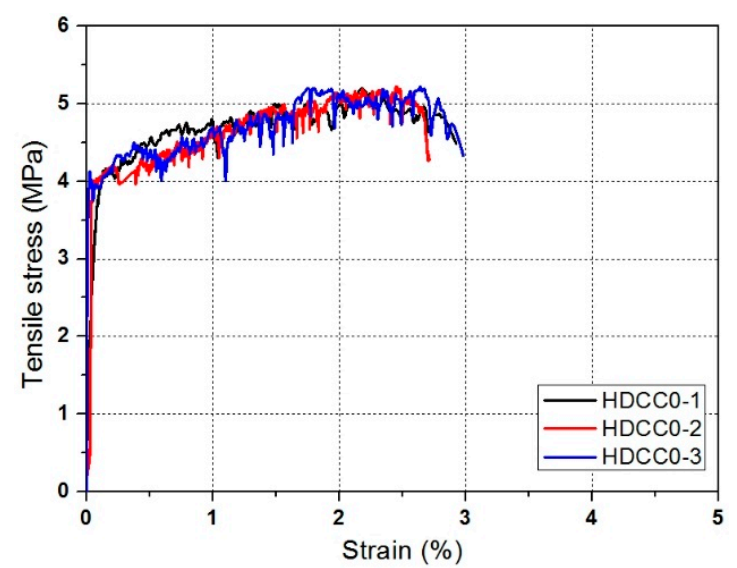

(a)

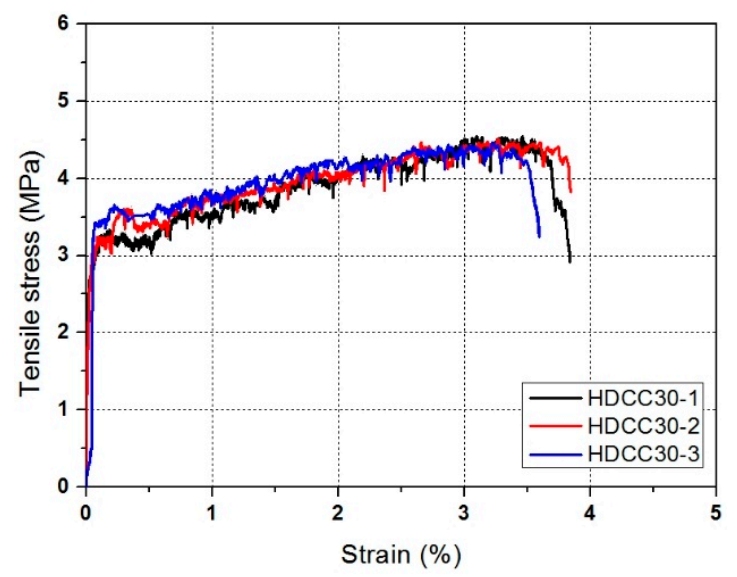

(c)

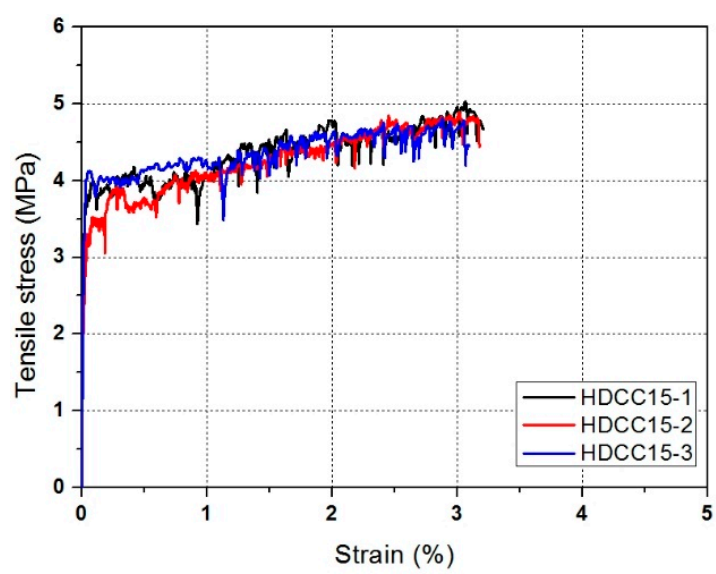

(b)

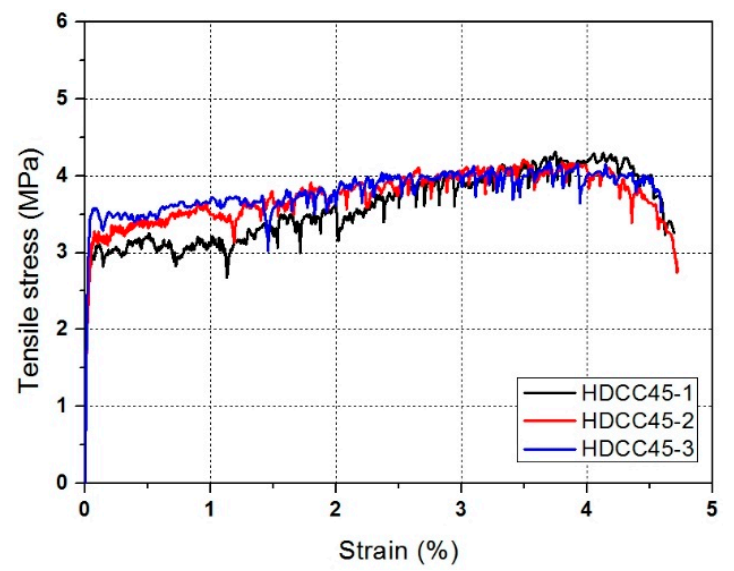

(d)

Figure 4. Tensile stress-strain curves in uniaxial tension: (a) HDCC0; (b) HDCC15; (c) HDCC30; and (d) HDCC45.

Table 3. Result of uniaxial tensile test.

\begin{tabular}{ccccc}
\hline Mixture & $\begin{array}{c}\text { Initial Cracking Strength } \\
\mathbf{( M P a )}\end{array}$ & $\begin{array}{c}\text { Tensile Strength } \\
\mathbf{( M P a )}\end{array}$ & $\begin{array}{c}\text { Tensile Strain Capacity } \\
\mathbf{( \% )}\end{array}$ & $\begin{array}{c}\text { Stress Performance } \\
\text { Index }\end{array}$ \\
\hline HDCC0 & $4.0 \pm 0.22$ & $5.1 \pm 0.17$ & $2.6 \pm 0.13$ & 1.28 \\
HDCC15 & $3.7 \pm 0.17$ & $4.8 \pm 0.21$ & $3.1 \pm 0.16$ & 1.30 \\
HDCC30 & $3.2 \pm 0.18$ & $4.3 \pm 0.22$ & $3.7 \pm 0.09$ & 1.34 \\
HDCC45 & $2.6 \pm 0.13$ & $3.5 \pm 0.16$ & $4.2 \pm 0.13$ & 1.35 \\
\hline
\end{tabular}

The tensile strength depends on the properties of the fibers and interfacial properties between the fiber and the matrix, as well as the matrix properties. Therefore, the tensile strength of composites generally decreases with decrease in the strength of the matrix. This results in decreased bonding strength between the fiber and the matrix, when the fiber properties are the same. Although the tensile strength of each mixture decreased with increase of the replacement ratio of cement with limestone powder, the ratios of tensile strength to compressive strength slightly increased with increase 
in the replacement ratio of limestone powder. The ratios of tensile strength to compressive strength of each mixture HDCC0, HDCC15, HDCC 30 , and HDCC45, were 10.5\%, 10.7\%, 11.1\% and $11.2 \%$, respectively. The ratios of tensile strength to initial cracking strength also increased with an increase in the replacement ratio of limestone powder. The ratios of tensile strength to initial cracking strength of each mixture HDCC0, HDCC15, HDCC30, and HDCC45, were 1.28, 1.30, 1.34, and 1.35, respectively.

Kanda and $\mathrm{Li}$ (2006) proposed practical criteria for saturated pseudo-strain hardening behavior of composites [24]. They proposed performance indices (i.e., stress performance index and energy performance index), both of which must be larger than unity to achieve saturated pseudo-strain hardening behavior. The stress performance index was defined as the ratio of the peak fiber bridging stress to the initial cracking strength. The peak fiber bridging stress is identical to the tensile strength of the composite. When this condition is satisfied, multiple-cracking behavior can be ensured. The higher the stress performance index is, the higher the potential for multiple-cracking behavior and the higher the tensile strain capacity. The tensile strain capacity increased as the stress performance index increased. All mixtures showed several hundred times higher tensile strain capacity than normal concrete, of which the tensile strain capacity is approximately $0.01 \%$. From these test results and analysis, it can be confirmed that the stress performance index can be adopted when designing the mixture and evaluating a composite incorporating limestone powder. Regarding the energy performance index, it is necessary to take into account complementary energy in the fiber bridging curves and matrix fracture toughness, which will be discussed in the section on micromechanical analysis.

\subsection{Interfacial Properties between the Fiber and the Matrix}

The interfacial properties (i.e., the chemical bond strength $\left(G_{d}\right)$ and frictional bond strength $\left(\tau_{0}\right)$ between the matrix and fiber) are listed in Table 4. It was observed that the chemical bond strength was not significantly influenced by the replacement of cement with limestone powder within the limited range of this study. The maximum absolute difference of chemical bond strength between the control mixture (HDCC0), and other mixtures incorporating limestone powder, was $0.6 \%$. This is attributable to the fact that the chemical structures between the surface of the fiber and matrix were not changed because all mixtures have same amount of water. On the other hand, the frictional bond strength decreased gradually as the replacement ratio of cement with limestone powder increased. While fiber pullout was occurring, the damaged fiber surface was caught in the matrix, creating friction force against fiber-pullout; thus, the friction force is dependent on the matrix strength. The matrix strength decreased with an increase in the replacement ratio of limestone powder, leading to decrease of the frictional bond strength. The frictional bond strength of the HDCC45 mixture was lower by $38.4 \%$, compared to the HDCC0 (control) mixture.

Table 4. Interfacial properties between the fiber and the matrix.

\begin{tabular}{ccc}
\hline Mixture & $G_{\boldsymbol{d}}(\mathbf{M P a})$ & $\boldsymbol{\tau}_{\mathbf{0}}\left(\mathrm{J} / \mathbf{m}^{\mathbf{2}}\right)$ \\
\hline HDCC0 & $1.874 \pm 0.05$ & $0.854 \pm 0.02$ \\
HDCC15 & $1.863 \pm 0.04$ & $0.744 \pm 0.01$ \\
HDCC30 & $1.877 \pm 0.06$ & $0.621 \pm 0.04$ \\
HDCC45 & $1.869 \pm 0.04$ & $0.526 \pm 0.05$ \\
\hline
\end{tabular}

\subsection{Matrix Fracture Toughness}

The fracture toughness values of each mixture are listed in Table 5. The matrix fracture toughness $\left(K_{m}\right)$ for mode I decreased gradually as the replacement ratio of cement with limestone powder increased. The fracture toughness of the HDCC 45 mortar mixture was lower by $48.2 \%$ than that of 
the HDCC 0 mortar mixture. The fracture energy $\left(J_{\text {tip }}\right)$ is defined as the energy consumed by crack propagation and can be calculated using Equation (3).

$$
J_{\text {tip }}=\frac{K_{m}^{2}}{E_{c}}
$$

where $E_{c}$ is the elastic modulus obtained from the compressive test of matrix. The fracture energy of the HDCC 45 mortar mixture was lower by $68.3 \%$ than that of the HDCC0 mortar mixture. Increased replacement ratio of the limestone powder caused reduced compressive strength and fracture toughness of the matrix.

Table 5. Fracture toughness of HDCC mortar.

\begin{tabular}{ccc}
\hline Mixture & $\boldsymbol{K}_{\mathbf{m}}\left(\mathbf{M P a} \cdot \mathbf{m}^{\mathbf{1 / 2}}\right)$ & $\boldsymbol{J}_{\text {tip }}\left(\mathbf{J} / \mathbf{m}^{\mathbf{2}}\right)$ \\
\hline HDCC0 & $1.065 \pm 0.06$ & $8.2 \pm 0.15$ \\
HDCC15 & $0.821 \pm 0.03$ & $6.0 \pm 0.21^{\prime}$ \\
HDCC30 & $0.679 \pm 0.04$ & $4.1 \pm 0.17$ \\
HDCC45 & $0.552 \pm 0.03$ & $2.6 \pm 0.24$ \\
\hline
\end{tabular}

\section{Micromechanical Analysis}

Figure 5 shows a typical fiber bridging curve and conditions for pseudo strain-hardening behavior with multiple cracks, and controlled crack width [25]. Marshall and Cox (1988) proposed the energy criterion for steady-state matrix-cracking of composites, which is expressed as Equation (4) [9]. The complementary energy $\left(J_{b}^{\prime}\right.$ : gray shaded area in Figure 5$)$ in the fiber bridging curve must be higher than the matrix fracture energy ( $J_{t i p}$ : blue shaded area in Figure 5). It can be explained physically that the energy required to increase the crack width in the composite should be higher than that required for crack propagation in the matrix.

$$
J_{\text {tip }} \leq \sigma_{0} \delta_{0}-\int_{0}^{\delta_{0}} \sigma(\delta) d \delta \equiv J_{b^{\prime}}^{\prime}
$$

where $\sigma_{0}$ is the maximum fiber bridging stress and $\delta_{0}$ is the crack opening corresponding to $\sigma_{0}$ on the fiber bridging curve.

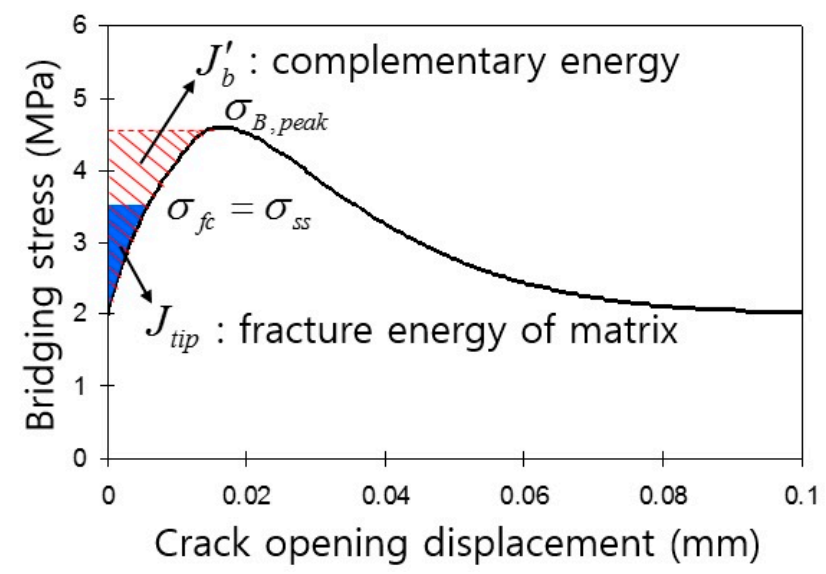

Figure 5. Typical fiber bridging curve for a strain hardening composite (adapted from [26]).

Figure 6 shows the fiber-bridging curves of each mixture, which were calculated theoretically by numerical analysis $[26,27]$ according to micromechanics based on micromechanical parameters (i.e., fiber, matrix, and fiber/matrix interfacial properties) obtained by single fiber pullout and matrix 
fracture toughness tests. The complementary energies were also calculated from the theoretical fiber bridging curves listed in Table 6. Although peak fiber bridging stress decreased with an increase of the replacement ratio of cement with limestone powder, the complementary energy increased with an increase of the replacement ratio of cement with limestone powder.

Table 6. Complementary energy of HDCCs.

\begin{tabular}{ccc}
\hline Mixture & $\boldsymbol{J}_{\boldsymbol{b}}^{\prime}\left(\mathbf{J} / \mathbf{m}^{\mathbf{2}}\right)$ & $\boldsymbol{R}_{\mathrm{E}}\left(\boldsymbol{J}_{\boldsymbol{b}}^{\prime} / \boldsymbol{J}_{\text {tip }}\right)$ \\
\hline HDCC0 & 39.1 & 4.8 \\
HDCC15 & 43.1 & 7.2 \\
HDCC30 & 45.4 & 10.9 \\
HDCC45 & 47.6 & 17.8 \\
\hline
\end{tabular}

The energy performance index $\left(R_{E}\right)$ proposed by Kanda and $\mathrm{Li}$ (2006) [24] is defined as the ratio of the complementary energy to the fracture energy of a matrix. It is known that when $R_{E}$ is over 3.0, multiple micro-cracking can be ensured. The $R_{E}$ values of all the HDCC mixtures were higher than 3.0, properly satisfying the energy condition. The $R_{E}$ value of the HDCC0 specimen was 4.8; however, this was the lowest value among all the specimens. On the other hand, the HDCC45 mixture exhibited the largest $R_{E}$ (17.8), which is 3.7 times higher than that of the HDCC0 mixture. The $R_{E}$ values increased sequentially as the replacement ratio of cement with limestone powder increased, which means that the potential of steady state cracking behavior increases with an increase of the replacement ratio. As described in Section 3.1, the stress performance index also increased with an increase in the replacement ratio. Overall, the replacement of cement with limestone powder increased the tensile strain capacity and the potential of saturated pseudo-strain hardening behavior, although it also induced some loss of strength. Micromechanical tests and analysis supported the tensile behavior and fundamental mechanisms of the HDCC mixtures investigated in this study.

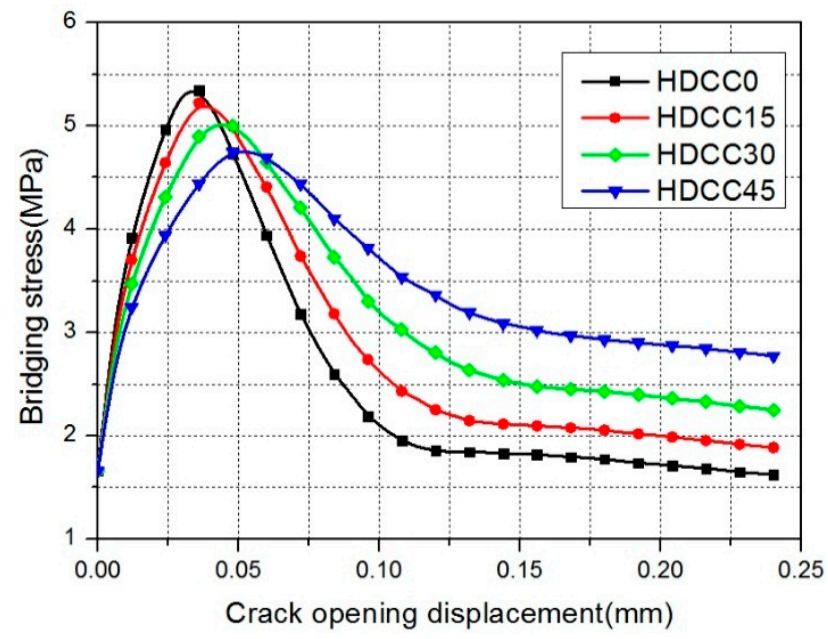

Figure 6. Bridging stress-crack opening displacement relationship of HDCCs.

\section{Conclusions}

This study investigated experimentally the effect of limestone powder on the composite properties and micromechanical parameters of HDCC in which the cement was partially replaced by limestone powder. From the test results, the following conclusions were drawn.

1. The compressive strength of the mixtures decreased as the replacement ratio of cement with limestone powder increased. The HDCC 45 mixture, in which $45 \%$ of the cement was replaced by limestone powder, showed compressive strength over $30 \mathrm{MPa}$ at the age of 28 days, which is the strength value widely used for structural concrete. 
2. Although the initial cracking strength and tensile strength of the mixtures decreased with an increase of the replacement ratio of cement with limestone powder, the ratio of tensile strength to initial cracking strength, which is expressed as the stress performance index, increased with an increase of the replacement ratio of cement with limestone powder. It was observed that the tensile strain capacity increased as the stress performance index increased. The tensile strength of HDCC45 was lower by $35 \%$ than that of HDCC 0 . On the other hand, the tensile strain capacity of HDCC 45 was higher by $62 \%$ than that of HDCC 0 .

3. It was observed that the frictional bond strength between the PVA fiber and the matrix, and the fracture energy of the mortar, decreased with an increase of the replacement ratio of cement with limestone powder. The frictional bond strength of the HDCC 45 mixture was lower by $38 \%$ than that of HDCC 0 mixture, and the fracture energy of the HDCC 45 mortar mixture was lower by $68.3 \%$ than that of HDCC0 mortar mixture. On the other hand, the effect of replacement of cement with limestone powder on the chemical bond strength was negligible.

4. Micromechanical analysis confirmed that all the mixtures investigated in this study satisfied the strength condition and the energy condition for saturated pseudo-strain hardening behavior of the composite. The stress performance index and the energy performance index of the mixtures increased sequentially as the replacement ratio of cement with limestone powder increased. The energy performance index of the HDCC45 mixture was 17.8, 3.7 times higher than that of the HDCC0 mixture.

Acknowledgments: This research was supported by Basic Science Research Program through the National Research Foundation of Korea (NRF) funded by the Ministry of Science and ICT (No. 2016R1A2B4011810).

Author Contributions: Jung Hwan Hyun and Yun Yong Kim conceived and designed the experiments; Jung Hwan Hyun performed the experiments; Bang Yeon Lee and Yun Yong Kim analyzed the data; Jung Hwan Hyun and Bang Yeon Lee wrote the paper.

Conflicts of Interest: The authors declare no conflict of interest.

\section{References}

1. Foti, D. Innovative techniques for concrete reinforcement with polymers. Constr. Build. Mater. 2016, 112, 202-209. [CrossRef]

2. Foti, D.; Paparella, F. Impact behavior of structural elements in concrete reinforced with pet grids. Mech. Res. Commun. 2014, 57, 57-66. [CrossRef]

3. Sutherland, R.; Humm, D.; Chrimes, M. Historic Concrete: Background to Appraisal; Thomas Telford: London, UK, 2001.

4. Li, V.C. On engineered cementitious composites (ecc). J. Adv. Concr. Technol. 2003, 1, 215-230. [CrossRef]

5. Kim, J.-K.; Kim, J.-S.; Ha, G.J.; Kim, Y.Y. Tensile and fiber dispersion performance of ecc (engineered cementitious composites) produced with ground granulated blast furnace slag. Cem. Concr. Res. 2007, 37, 1096-1105. [CrossRef]

6. Choi, J.-I.; Lee, B. Bonding properties of basalt fiber and strength reduction according to fiber orientation. Materials 2015, 8, 6719-6727. [CrossRef] [PubMed]

7. Lee, Y.; Choi, J.-I.; Kim, H.-K.; Lee, B.Y. Effects of a defoamer on the compressive strength and tensile behavior of alkali-activated slag-based cementless composite reinforced by polyethylene fiber. Compos. Struct. 2017, 172, 166-172. [CrossRef]

8. Li, V.C.; Wang, Y.; Backer, S. A micromechanical model of tension-softening and bridging toughening of short random fiber reinforced brittle matrix composites. J. Mech. Phys. Solids 1991, 39, 607-625. [CrossRef]

9. Marshall, D.; Cox, B. A j-integral method for calculating steady-state matrix cracking stresses in composites. Mech. Mater. 1988, 7, 127-133. [CrossRef]

10. Damtoft, J.; Lukasik, J.; Herfort, D.; Sorrentino, D.; Gartner, E. Sustainable development and climate change initiatives. Cem. Concr. Res. 2008, 38, 115-127. [CrossRef]

11. De Weerdt, K.; Kjellsen, K.; Sellevold, E.; Justnes, H. Synergy between fly ash and limestone powder in ternary cements. Cem. Concr. Compos. 2011, 33, 30-38. [CrossRef]

12. Heikal, M.; El-Didamony, H.; Morsy, M. Limestone-filled pozzolanic cement. Cem. Concr. Res. 2000, 30, 1827-1834. [CrossRef] 
13. Lothenbach, B.; Le Saout, G.; Gallucci, E.; Scrivener, K. Influence of limestone on the hydration of portland cements. Cem. Concr. Compos. 2008, 38, 848-860. [CrossRef]

14. Ramezanianpour, A.A.; Ghiasvand, E.; Nickseresht, I.; Mahdikhani, M.; Moodi, F. Influence of various amounts of limestone powder on performance of portland limestone cement concretes. Cem. Concr. Compos. 2009, 31, 715-720. [CrossRef]

15. Tsivilis, S.; Tsantilas, J.; Kakali, G.; Chaniotakis, E.; Sakellariou, A. The permeability of portland limestone cement concrete. Cem. Concr. Res. 2003, 33, 1465-1471. [CrossRef]

16. Voglis, N.; Kakali, G.; Chaniotakis, E.; Tsivilis, S. Portland-limestone cements. Their properties and hydration compared to those of other composite cements. Cem. Concr. Compos. 2005, 27, 191-196. [CrossRef]

17. Felekoglu, B. Utilisation of high volumes of limestone quarry wastes in concrete industry (self-compacting concrete case). Resour. Conserv. Recycl. 2007, 51, 770-791. [CrossRef]

18. Zhou, J.; Qian, S.; Beltran, M.G.S.; Ye, G.; van Breugel, K.; Li, V.C. Development of engineered cementitious composites with limestone powder and blast furnace slag. Mater. Struct. 2010, 43, 803-814. [CrossRef]

19. JSCE (Japan Society of Civil Engineers). Recommendations for Design and Construction of High Performance Fiber Reinforced Cement Composites with Multiple Fine Cracks (HPFRCC); Japan Society of Civil Engineers: Tokyo, Japan, 2008.

20. ASTM International. Standard Test Method for Compressive Strength of Cylindrical Concrete Specimens. In Annual Book of ASTM Standards; ASTM C39/C39M-15; American society for Testing and Materials: West Conshohocken, PA, USA, 2015. [CrossRef]

21. Redon, C.; Li, V.C.; Wu, C.; Hoshiro, H.; Saito, T.; Ogawa, A. Measuring and modifying interface properties of pva fibers in ecc matrix. J. Mater. Civ. Eng. 2001, 13, 399-406. [CrossRef]

22. ASTM International. Standard Test Method for Linear-Elastic Plane-Strain Fracture Toughness $K_{I c}$ of Metallic Materials. In Annual Book of ASTM standards; ASTM E399; American Society for Testing and Materials: West Conshohocken, PA, USA, 2012.

23. Kanda, T.; Li, V.C. Effect of fiber strength and fiber-matrix interface on crack bridging in cement composites. J. Eng. Mech. 1999, 125, 290-299. [CrossRef]

24. Kanda, T.; Li, V.C. Practical design criteria for saturated pseudo strain hardening behavior in ecc. J. Adv. Concr. Technol. 2006, 4, 59-72. [CrossRef]

25. Rizzuti, L.; Bencardino, F. Effects of fibre volume fraction on the compressive and flexural experimental behaviour of sfrc. Cont. Eng. Sci. 2014, 7, 379-390. [CrossRef]

26. Lee, B.Y.; Lee, Y.; Kim, J.K.; Kim, Y.Y. Micromechanics-based fiber-bridging analysis of strain-hardening cementitious composite accounting for fiber distribution. CMES-Comp. Model. Eng. Sci. 2010, 61, 111-132.

27. Yang, E.-H.; Wang, S.; Yang, Y.; Li, V.C. Fiber-bridging constitutive law of engineered cementitious composites. J. Adv. Concr. Technol. 2008, 6, 181-193. [CrossRef] 